\title{
Mortality from multiple sclerosis and exposure to residential and occupational solar radiation: a case-control study based on death certificates
}

\author{
D Michal Freedman, Mustafa Dosemeci, Michael C R Alavanja
}

\begin{abstract}
Objectives-To explore whether mortality from multiple sclerosis is negatively associated with exposure to sunlight.

Methods-Two case-control studies based on death certificates were conducted for mortality from multiple sclerosis and non-melanoma skin cancer (as a positive control) to examine associations with residential and occupational exposure to sunlight. Cases were all deaths from multiple sclerosis between 1984 and 1995 in 24 states of the United States. Controls, which were age frequency matched to a series of cases, excluded cancer and certain neurological deaths. The effects of occupational exposure to sunlight were assessed among subjects with usual occupations requiring substantial activity, so as to exclude those whose indoor jobs resulted from disabilities subsequent to the onset of the disease. Multiple logistic regression analyses were applied, with adjustment for age, sex, race, and socioeconomic status.
\end{abstract}

Results-Unlike mortality from skin cancer, mortality from multiple sclerosis was negatively associated with residential exposure to sunlight (odds ratio $(\mathrm{OR})=0.53$ (multiple sclerosis) and $\mathrm{OR}=1.24$ (skin cancer)). Odds ratios for the highest occupational exposure to sunlight were 0.74 (95\% confidence interval $(95 \% \mathrm{CI})$ 0.61 to 0.89 ) for mortality from multiple sclerosis, compared with 1.21 (1.09 to 1.34$)$ for mortality from non-melanoma skin cancer. The OR was 0.24 for the combined effect of the highest levels of residential and occupational exposure to sunlight on multiple sclerosis, compared with an OR of 1.38 for skin cancer.

Conclusions-In this exploratory study, mortality from multiple sclerosis, unlike mortality from skin cancer, was negatively associated with both residential and occupational exposure to sunlight.

(Occup Environ Med 2000;57:418-421)

Keywords: multiple sclerosis; aetiology; latitude; ultraviolet radiation; sunlight; occupation; residence; skin cancer

Epidemiology Branch

M Dosemeci

M C R Alavanja

Correspondence to: Dr D Michal Freedman mf101e@nih.gov

Accepted 26 January 2000
Little is known about the aetiology of multip that increased risk may be related to higher socioeconomic factors, ${ }^{1}$ viral infections, environmental influences before the age of 15 , and genetics, among other factors. ${ }^{12}$ Many epidemiological studies have also found a positive association between multiple sclerosis and residential latitude in the United States and other parts of the world..$^{3-9}$ Whether the geographical association reflects a strong role for environmental risk factors, and what those factors might be, remains unclear. Some investigators have suggested that the geographical gradient of multiple sclerosis may reflect the role of sunlight in the aetiology of disease. ${ }^{510-13}$

In a report which hypothesed that ultraviolet radiation explains the latitude gradient in multiple sclerosis, McMichael and Hall ${ }^{10}$ predicted that if ultraviolet radiation is an aetiological agent, outdoor occupations would be expected to protect against multiple sclerosis. To our knowledge, conditions related to residence or latitude have been the sole indicators of solar radiation explored in epidemiological studies of multiple sclerosis. We conducted a casecontrol study based on death certificates about mortality from multiple sclerosis in the United States, to explore the effects of potential residential as well as occupational exposure to sunlight. The findings for multiple sclerosis were compared with findings for nonmelanoma skin cancer, which has been causally linked to sunlight, ${ }^{14}{ }^{15}$ and served as a positive control.

\section{Materials and methods}

The National Cancer Institute, the National Institute for Occupational Safety and Health, and the National Center for Health Statistics maintain a database of all deaths in 24 states, which coded occupation, state of residence at birth and at death, and other information from death certificates, as described by Figgs et al. ${ }^{16}$ Cases included all underlying causes of deaths between 1984 and 1995 from multiple sclerosis (international classification of diseases, ninth revision (ICD-9), code 340) and nonmelanoma skin cancer (code 173). A common set of controls was used across a series of casecontrol studies on neurological and cancer mortality (including breast, prostate, ovarian, and colon cancer) and solar radiation. Deaths from cancer (ICD 140-239), multiple sclerosis (ICD 340), and some diseases of the central nervous system (ICD 330-337), were excluded. Controls were frequency matched by five year age group to the combined group of multiple sclerosis, non-melanoma skin cancer, and other causes of death of the cases in the series. The controls represent a one to one ratio with the most common cause of death in the 
series (colon cancer), but a ratio of about 25 to one with multiple sclerosis and with skin cancer. The data were also analysed with an alternative subset of controls, excluding those with deaths due to heart disease or accidents, causes which may be related to residential region. ${ }^{17} 18$

Residential exposure to sunlight was assessed by state residence recorded on the death certificate. We assigned each state one of three levels of solar radiation based on United States Weather Bureau data. ${ }^{19}$ Subjects were limited to those who resided in the same solar radiation region at birth and at death to reduce misclassification in analyses based on lifetime residential solar exposure. This included 4282 cases of

Table 1 Characteristics of multiple sclerosis cases and controls (n (\%)) of participants, USA, 1984-95

\begin{tabular}{|c|c|c|c|}
\hline Characteristics & $\begin{array}{c}\text { Multiple sclerosis } \\
(n=5701(4 \%))\end{array}$ & $\begin{array}{l}\text { Skin cancer } \\
(n=6565(4 \%))\end{array}$ & $\begin{array}{l}\text { Controls } \\
(n=153502(96 \%))\end{array}$ \\
\hline \multicolumn{4}{|l|}{ Age: } \\
\hline$<50$ & $1673(29)$ & $616(9)$ & $14704(10)$ \\
\hline $50-69$ & $2784(49)$ & $2315(35)$ & $48312(31)$ \\
\hline$\geqslant 70$ & $1244(22)$ & $3634(55)$ & $90486(59)$ \\
\hline \multicolumn{4}{|l|}{ Sex: } \\
\hline Female & $3604(63)$ & 2073(32) & $70081(46)$ \\
\hline Male & 2097(37) & $4492(68)$ & $83421(54)$ \\
\hline \multicolumn{4}{|l|}{ Race and origin ${ }^{\star}$ : } \\
\hline Black & $464(8)$ & $596(9)$ & $18699(12)$ \\
\hline White northern European ancestry & $232(4)$ & $220(3)$ & $5299(3)$ \\
\hline White other ancestry & 4993(88) & $5710(87)$ & $127980(83)$ \\
\hline Other & $12(<1)$ & $39(<1)$ & $1524(1)$ \\
\hline \multicolumn{4}{|l|}{ Residence sunlight $\dagger$ : } \\
\hline Low & $2160(38)$ & $1789(27)$ & $45473(30)$ \\
\hline Moderate & $2025(36)$ & $2738(42)$ & $63958(42)$ \\
\hline High & $1516(27)$ & $2035(31)$ & $44005(29)$ \\
\hline \multicolumn{4}{|l|}{ Urban or rural: } \\
\hline Metropolitan & $4025(71)$ & $4211(64)$ & $97893(64)$ \\
\hline Non-metropolitan & $1676(29)$ & $2351(36)$ & $55460(36)$ \\
\hline \multicolumn{4}{|l|}{ Occupation‡: } \\
\hline Indoor & $2865(50)$ & $3024(46)$ & $71529(47)$ \\
\hline Mixed & $674(12)$ & $1356(21)$ & $26797(17)$ \\
\hline Outdoor & $159(3)$ & $784(12)$ & $12708(8)$ \\
\hline Other $\ddagger$ & $2003(35)$ & $1401(21)$ & $42468(28)$ \\
\hline \multicolumn{4}{|l|}{ Socioeconomic status: } \\
\hline 1 Low & $360(6)$ & $1105(17)$ & $22112(14)$ \\
\hline 2 & $578(10)$ & $1198(18)$ & $26184(17)$ \\
\hline 3 & $1596(28)$ & $1800(27)$ & $40017(26)$ \\
\hline 4 & $900(16)$ & $776(12)$ & $17944(12)$ \\
\hline 5 High & $264(5)$ & $285(4)$ & $4777(3)$ \\
\hline \multirow{2}{*}{\multicolumn{4}{|c|}{$\begin{array}{l}2003(35) \\
\text { Subpopulations analysed in the study }\end{array}$}} \\
\hline & & & \\
\hline Residence sunlight (lifetime) $\int$ & $\mathrm{n}=4282$ & $n=4929$ & $\mathrm{n}=115195$ \\
\hline Low & $1811(42)$ & $1321(27)$ & $33696(29)$ \\
\hline Moderate & $1552(36)$ & $2198(45)$ & $50252(44)$ \\
\hline High & $919(21)$ & $1410(29)$ & $31247(27)$ \\
\hline Occupation (active) & $\mathrm{n}=1562$ & $\mathrm{n}=2849$ & $\mathrm{n}=59690$ \\
\hline Indoor & $982(63)$ & $1262(44)$ & $31492(53)$ \\
\hline Mixed & $425(27)$ & $819(29)$ & $15708(26)$ \\
\hline Outdoor & $155(10)$ & $768(27)$ & $12490(21)$ \\
\hline
\end{tabular}

${ }^{\star}$ Origin was characterised as northern European if the death certificate identified national origin as British, Irish, German, Scandinavian, Polish, or other northern European.

†Residence at time of death. Levels of sun exposure were categorised based on annual mean daily solar radiation reported by Garland $e t a l^{19}$ for state reported as residence. Residence was sometimes outside the 24 states in which deaths occurred. Low=generally included states falling within the solar radiation contour lines for annual mean daily solar radiation $<350 \mathrm{gm}-\mathrm{cal} / \mathrm{cm}^{2}$ and included the following states and other areas: Alaska, Connecticut, Maine, Massachusetts, Michigan, Minnesota, New Hampshire, New York, Ohio, Oregon, Pennsylvania, Rhode Island, Vermont, Washington, Wisconsin, Canada; moderate $=>350-400 \mathrm{gm}-\mathrm{cal} / \mathrm{cm}^{2}$ and included Arkansas, Delaware, District of Columbia, Idaho, Illinois, Indiana, Iowa, Kansas, Kentucky, Maryland, Missouri, Montana, Nebraska, New fersey, North Carolina, North Dakota, South Dakota, Tennessee, Virginia, and West Virginia; and high $=>400 \mathrm{gm}-\mathrm{cal} / \mathrm{cm}^{2}$ and included Alabama, Arizona, California, Colorado, Florida, Georgia, Hawaii, Louisiana, Mississippi, Nevada, Nerw Mexico, Oklahoma, South Carolina, Texas, Utah, Wyoming, Puerto Rico, Virgin Islands, Guam, Cuba, and Mexico. (States in italics are the 24 states that form the mortality database.)

$\ddagger$ Other included homemakers, retirees, students, volunteers, and those with unknown or no occupation.

§Residence sunlight (lifetime) included only those whose residential solar radiation was the same at birth and at death as already defined.

- Occupational analysis was limited to those subjects whose usual occupation was classified as highly or moderately active to exclude those whose indoor jobs reflected restricted job options due to the disabilities of their disease. Homemakers were also excluded. multiple sclerosis, 4929 skin cancer cases, and 115195 controls (about $75 \%$ of each).

Occupational exposure to sunlight was based on usual occupation classified by an industrial hygienist (MD) into three categories: indoor work, work that combined indoor and outdoor exposure, and outdoor work. Occupation was also used to assess socioeconomic status based on a method of scoring occupation developed by $\mathrm{Green}^{20}$ and to create an index of occupational physical activity with four levels of physical activity. The effects of occupational exposure to solar radiation were assessed among all subjects and among the subjects in occupations categorised as requiring high or moderate levels of activity, so as to exclude those whose indoor jobs resulted from disabilities subsequent to onset of the disease. This resulted in $1562(27 \%)$ cases of multiple sclerosis, 2849 (43\%) cases of skin cancer, and 59690 (39\%) controls.

The effects of ethnic origin and race were assessed by classifying subjects based on national origin and race as recorded on the death certificate. Northern European ancestry in particular was assessed because of its possible role in the higher risk previously found with higher latitudes in the US.

We used multivariate models of potential exposure to solar radiation, adjusting for age, sex, race, and socioeconomic status. The models were applied to the entire population; sex and race subpopulations (adjusting only for age and socioeconomic status); as well as subpopulations of residents of eastern and western states (to examine whether possible ethnic differences between eastern and western regions accounted for any observed patterns).

The measures of association were the mortality odds ratio (OR) and 95\% confidence interval $(95 \% \mathrm{CI})$ derived by standard logistic regression methods in SAS. ${ }^{21}$

\section{Results}

Table 1 provides the characteristics of cases and controls for deaths from multiple sclerosis and non-melanoma skin cancer, as well as for those with the same residential region at birth and at death, and the group with active occupations. Of those with active occupations, about $10 \%$ of cases of multiple sclerosis had outdoor jobs.

Residence in states with the highest potential exposure to sunlight was associated with an adjusted OR for multiple sclerosis of 0.53 (table 2). By contrast, the adjusted OR for skin cancer and residential exposure to solar radiation increased significantly to 1.24 in the highest exposure category. When the country was stratified into eastern and western regions, the risk of mortality from multiple sclerosis declined with increasing residential solar radiation in each region, with the east showing a stronger negative gradient ( $\mathrm{OR}=0.28$ (east) and $\mathrm{OR}=0.63$ (west) for highest exposure.) The negative gradient was also found in the subpopulations of white men, white women, black men, and black women (adjusted $\mathrm{OR}=0.57,0.49,0.44,0.59$ respectively for highest exposure). Among white people, family 
Table 2 Crude and adjusted ORs (95\% CIs) for mortality from multiple sclerosis associated with indicators of exposure to sunlight and socioeconomic status, USA, 1984-95

\begin{tabular}{|c|c|c|c|c|}
\hline & \multicolumn{2}{|l|}{ Multiple sclerosis } & \multicolumn{2}{|l|}{ Skin cancer } \\
\hline & Crude & Adjusted ${ }^{\star}$ & Crude & Adjusted ${ }^{\star}$ \\
\hline \multicolumn{5}{|c|}{ Residence sunlight $\dagger$ : } \\
\hline Low & 1.0 & 1.0 & 1.0 & 1.0 \\
\hline Moderate & $0.58(0.54$ to 0.62$)$ & $0.59(0.55$ to 0.63$)$ & $1.12(1.04$ to 1.20$)$ & $1.15(1.07$ to 1.23$)$ \\
\hline High & $0.55(0.51$ to 0.59$)$ & $0.53(0.48$ to 0.57$)$ & $1.15(1.07$ to 1.24$)$ & $1.24(1.15$ to 1.35$)$ \\
\hline \multicolumn{5}{|l|}{ Occupation $¥:$} \\
\hline Indoor & 1.0 & 1.0 & 1.0 & 1.0 \\
\hline Mixed & 0.87 (0.77 to 0.97$)$ & 0.89 (0.78 to 1.02$)$ & $1.30(1.19$ to 1.42$)$ & $1.03(0.93$ to 1.14$)$ \\
\hline Outdoor & $0.40(0.33$ to 0.47$)$ & $0.74(0.61$ to 0.89$)$ & $1.53(1.40$ to 1.68$)$ & $1.21(1.09$ to 1.34$)$ \\
\hline \multicolumn{5}{|c|}{ Socioeconomic status: } \\
\hline 1 Low & 1.0 & 1.0 & 1.0 & 1.0 \\
\hline 2 & $1.36(1.19$ to 1.55$)$ & $1.00(0.88$ to 1.15$)$ & $0.92(0.84$ to 1.0$)$ & $0.93(0.85$ to 1.01$)$ \\
\hline 3 & $2.45(2.19$ to 2.75$)$ & $1.90(1.68$ to 2.13$)$ & $0.90(0.83$ to 0.97$)$ & $0.89(0.82$ to 0.96$)$ \\
\hline 4 & $3.08(2.73$ to 3.49$)$ & $2.26(1.99$ to 2.57$)$ & $0.87(0.79$ to 0.95$)$ & $0.90(0.82$ to 1.00$)$ \\
\hline 5 High & 3.39 (2.89 to 3.99$)$ & $3.07(2.59$ to 3.62$)$ & $1.19(1.04$ to 1.36$)$ & $1.07(0.94$ to 1.23$)$ \\
\hline
\end{tabular}

*Adjusted ORs were calculated with logistic regression, adjusting for age, sex, race, and socioeconomic status, except in the case of socioeconomic status where adjustments were for age, sex, and race.

†Residence sunlight was defined as residing in a region both at birth and at the time of death. Regions are defined in table 1 . Subjects who resided in different regions at birth and at the time of death were excluded.

$\ddagger$ Occupational analysis was limited to those subjects whose usual occupation was classified as highly or moderately active to exclude those whose indoor jobs reflected restricted job options due to the disabilities of their disease. Homemakers were also excluded.

origin from a northern European country was not associated with risk of mortality from multiple sclerosis, after controlling for residence, age, sex, and socioeconomic status $(\mathrm{OR}=1.0)$.

Occupational solar radiation (among active jobs) was associated with reduced risk of mortality from multiple sclerosis (table 2). This association was generally found in racial and sex subpopulations, although the numbers of cases were especially small for minorities (data not shown). By contrast, occupational solar radiation was positively associated with risk of skin cancer in the total population, and generally among sex and race subpopulations (data not shown). We also found that the residential and occupational solar radiation gradient in risk remained in analyses with the alternative subset of controls.

Table 3 shows the combined effect of residential and occupational solar exposure among those in active jobs. With the referent category comprised of indoor workers in residential areas receiving least solar radiation, increased potential exposure to sunlight was generally associated with reduced risk of multiple sclerosis in each residential and occupational category. In the highest combined (occupational and residential) sunlight category, the OR was 0.24 (95\% CI 0.15 to 0.38 ).

Table 3 ORs $(95 \%$ CIs) for mortality from multiple sclerosis and skin cancer by exposure to occupational and residential sunlight, USA, 1984-95

\begin{tabular}{|c|c|c|c|}
\hline \multirow[b]{2}{*}{ Occupational exposure } & \multicolumn{3}{|c|}{ Residence sunlightt (cases; controls) } \\
\hline & Low & Moderate & High \\
\hline \multicolumn{4}{|l|}{ Multiple sclerosis: } \\
\hline Indoor & $\begin{array}{l}1.0 \\
(350 ; 7418)\end{array}$ & $\begin{array}{l}0.57(0.48 \text { to } 0.68) \\
(255 ; 10140)\end{array}$ & $\begin{array}{l}0.54(0.44 \text { to } 0.66) \\
(148 ; 5830)\end{array}$ \\
\hline Outdoor & $\begin{array}{l}0.89(0.64 \text { to } 1.22) \\
(50 ; 2249)\end{array}$ & $\begin{array}{l}0.52(0.38 \text { to } 0.71) \\
(58 ; 4875)\end{array}$ & $\begin{array}{l}0.24(0.15 \text { to } 0.38) \\
(20 ; 3428)\end{array}$ \\
\hline \multicolumn{4}{|l|}{ Skin cancer: } \\
\hline Indoor & $\begin{array}{l}1.0 \\
(301 ; 7418)\end{array}$ & $\begin{array}{l}1.08(0.92 \text { to } 1.26) \\
(409 ; 10140)\end{array}$ & $\begin{array}{l}1.17(0.98 \text { to } 1.41) \\
(227 ; 5830)\end{array}$ \\
\hline Outdoor & $\begin{array}{l}1.07(0.85 \text { to } 1.35) \\
(117 ; 2249)\end{array}$ & $\begin{array}{l}1.42(1.18 \text { to } 1.71) \\
(322 ; 4875)\end{array}$ & $\begin{array}{l}1.38(1.12 \text { to } 1.69) \\
(202 ; 3428)\end{array}$ \\
\hline
\end{tabular}

${ }^{\star}$ ORs were calculated with logistic regression, adjusting for age, sex, race, socioeconomic status, metropolitan residence, and occupational physical activity among subjects with high or moderate activity jobs. Homemakers were also excluded.

tResidence sunlight was defined as residing in a region both at birth and at the time of death Regions are defined in table 1 . Subjects who resided in different regions at birth and the time of death were excluded.
By contrast, the risks for skin cancer increased with potential occupational exposure to sunlight in each residential category, and with residential exposure among indoor workers, although not consistently among outdoor workers.

\section{Discussion}

By contrast with the mortality from skin cancer, our study found that both residential and occupational solar radiation were inversely associated with mortality from multiple sclerosis, and that the associations generally characterised sex and race subpopulations. Ethnicity does not seem to explain the geographical gradient because northern European ancestry was not a risk factor and a negative gradient was found in both eastern and western regions of the country, although it was weaker in the west. By assessing the effects of potential occupational exposure to solar radiation only among those with the most active jobs, we also increased the likelihood that the inverse association reflects causal factors, rather than occupational changes after the onset of disease.

Death certificate studies, such as this, have recognised limitations, including potential misclassification of occupation and residential exposure, and lack of information on potential confounders - such as viral infections, environmental childhood exposures, genetics, and other sources of exposure to sunlight. ${ }^{22}$ As noted, residence was based simply on place of birth and residence at death, whereas occupational exposure was limited to usual occupation. If the misclassification of cases does not differ from those of controls, any error in the association will at most reduce the association found between exposure and mortality.

One of the most problematic limitations is the potential bias in use of deaths rather than population as the study base, which may result in biased associations, unless the distribution of exposure of the dead controls reflects that of the living source or base population from which the cases came. ${ }^{23}$ Although the similarity of our findings with an alternative subset of controls 
supports the findings, uncertainties remain about whether the dead controls reflect the underlying exposure profile of the base population.

Despite these limitations, our study confirmed many of the findings previously reported. The validity of the solar radiation indices was supported by the positive association we found between the exposure to solar radiation and mortality from non-melanoma skin cancer, which is consistent with previous studies linking incidence of skin cancer to cumulative exposure to sun. ${ }^{15}$ Also, although socioeconomic status was based on usual occupation, and not on other possible indicators, the positive relation we found between socioeconomic status and risk of multiple sclerosis is consistent with other studies. ${ }^{25}{ }^{26}$ Our finding that northern European ancestry is not related to risk, after controlling for residence, is consistent with the results of Page et $a l^{27}$ in another of the veteran series studies.

Several mechanisms have been presented about how sunlight may affect multiple sclerosis. ${ }^{101113}$ Hayes et $a l^{11}$ proposed that the role of sunlight on immune function may be mediated by hormonal vitamin $\mathrm{D}$. Hutter and Laing $^{13}$ suggested that the effect of sunlight may be mediated by the secretion of melatonin, which is both sensitive to light and may affect the cellular structure of the thymus. McMichael and $\mathrm{Hall}^{10}$ also suggested that sunlight may suppress immune functions, either by reducing early $T$ cell sensitisation to antigens that mimic myelin or subsequent cell mediated responses to these antigens.

As our study was based on death certificates, our findings are necessarily exploratory. The negative associations between mortality from multiple sclerosis and both residential and occupational exposure to sunlight found here warrant future study based on incident cases and more refined assessments of exposure to sunlight.

We gratefully acknowledge the thoughtful comments of Dr Aaron Blair, Joanne Colt, Dr Joseph F Fraumeni Jr, Dr Rober $\mathrm{N}$ Hoover, and Dr Richard B Hayes on the manuscript.

1 Waksman BH. Multiple sclerosis. Curr Opin Immunol 1989;1:733-9.

2 Weinshenker BG. Epidemiology of multiple sclerosis. Neuroepidemiology 1996;14:291-308.

3 Lauer K. The risk of multiple sclerosis in the USA in relation to sociogeographic features: a factor-analytic study. f Clin Epidemiol 1998;47:43-8.
4 Kurtzke JF, Beebe GW, Norman JE Jr. Epidemiology of multiple sclerosis in US veterans: 1. Race, sex, and
geographic distribution. Neurology 1979;29:1228-35.

5 Acheson ED, Bachrach CA, Wright FM. Some comments on the relationship of the distribution of multiple sclerosis to latitude, solar radiation, and other variables. Acta Psychiat Scand 1960;35(suppl):132-47.

6 Ulett G. Geographic distribution of multiple sclerosis. Diseases of the Nervous System 1948;9:342-6.

7 Beebe GW, Kurtzke JF, Kurland LT, et al. Studies on the natural history of multiple sclerosis 3. Epidemiologic analysis of the army experience in world war II. Neurology 1967;17:1-17.

8 Miller DH, Hammond SR, McLeod JG, et al. Multiple sclerosis in Australia and New Zealand; are the determinants genetic or environmental? f Neurol Neurosurg Psychiatry 1990;53:903-5.

9 Norman JE Jr, Kurtzke JF, Beebe GW. Epidemiology of multiple sclerosis in US veterans: 2. Latitude, climate and the risk of multiple sclerosis. Fournal of Chronic Disease 1983;36:551-9.

10 McMichael AJ, Hall AJ. Does immunosuppressive ultraviolet radiation explain the latitude gradient for multiple sclerosis? Epidemiology 1997;8:642-5.

11 Hayes CE, Cantorna MT, Deluca HF. Vitamin D and multiple sclerosis. Proc Soc Exp Biol Med 1997;216:21-7.

12 Goldberg P. Multiple sclerosis: vitamin D and calcium as environmental determinants of prevalence. International fournal of Environmental Studies 1974;6:19-27.

13 Hutter CDD, Laing P. Multiple sclerosis: sunlight, diet, immunology and aetiology. Med Hypotheses 1996;46:6774.

14 Scotto J, Fears TR, Kraemer KH, et al. Non-melanoma skin cancer. In: Schottenfeld D, Fraumeni JF Jr, eds. Cancer epidemiology and prevention. New York: Oxford University Press, 1996:1313-30.

15 Glass AG, Hoover RN. The emerging epidemic of melanoma and squamous cell skin cancer. $7 A M A 1989$; 262:2097-100.

16 Figgs LW, Dosemeci M, Blair A. United States nonHodgkin's lymphoma surveillance by occupation 1984-9: a 24 state death certificate study. Am f Ind Med 1995;27: $817-35$.

17 Injury mortality atlas of the United States, 1979-87. MMWR Morb Mortal Wkly Rep 1991;40:846-8.

18 Lackland DT, Moore MA. Hypertension-related mortality and morbidity in the southeast. South Med f 1997;90:191-

19 Garland CF, Garland FC. Do sunlight and vitamin D reduce the likelihood of colon cancer? Int F Epidemiol 1980; 9:227-31.

20 Green LW. Manual for scoring socioeconomic status for research on health behavior. Public Health Rep 1970;85: $815-27$

21 Miettinen OS, Wang JD. An alternative to the proportionate mortality ratio. Am f Epidemiol 1981;114:144-8.

22 Lauer K. Ecologic studies of multiple sclerosis. Neurology 1997;49(suppl 2):S18-26.

23 Rothman KJ. Types of epidemiologic study. In: Modern epidemiology. Boston: Little Brown, 1986:51-76.

24 Kricker A, Armstrong BK, English DR. Sun exposure and non-melanocytic skin cancer. Cancer Causes Control 1994;5: $367-92$.

25 Kurtze JF, Page WF. Epidemiology of multiple sclerosis in US veterans: VII. Risk factors for MS. American Academy of Neurology 1997;48:204-13.

26 Casetta I, Granieri E, Malagu S, et al. Environmental risk factors and multiple sclerosis: a community-based, casecontrol study in the province of Ferrara, Italy. Neuroepidemiology 1994;13:120-8.

27 Page WF, Mack TM, Kurtze JF, et al. Epidemiology of multiple sclerosis in US veterans: 6. Population ancestry and surname ethnicity as risk factors for multiple sclerosis. Neuroepidemiology 1995;14:286-96.

\section{Rejected manuscripts}

Authors whose submitted articles are rejected will be advised of the decision and one copy of the article, together with any reviewer's comments, will be returned to them. The fournal will destroy remaining copies of the article but correspondence and reviewers' comments will be kept. 